\title{
Sensitivity and specificity of the 'knee-up test' for estimation of the American Spinal Injury Association Impairment Scale in patients with acute motor incomplete cervical spinal cord injury
}

\author{
Itaru Yugué ${ }^{1}$ Seiji Okada ${ }^{2}$ Takeshi Maeda ${ }^{1}$ Takayoshi Ueta ${ }^{1} \cdot$ Keiichiro Shiba ${ }^{1}$
}

Received: 20 July 2017 / Revised: 13 November 2017 / Accepted: 20 November 2017 / Published online: 28 December 2017

(c) International Spinal Cord Society 2018

\begin{abstract}
Study design A retrospective study.

Objective Precise classification of the neurological state of patients with acute cervical spinal cord injury (CSCI) can be challenging. This study proposed a useful and simple clinical method to help classify patients with incomplete CSCI.

Setting Spinal Injuries Centre, Japan.

Methods The sensitivity and specificity of the 'knee-up test' were evaluated in patients with acute CSCI classified as American Spinal Injury Association Impairment Scale (AIS) C or D. The result is positive if the patient can lift the knee in one or both legs to an upright position, whereas the result is negative if the patient is unable to lift the knee in either leg to an upright position. The AIS of these patients was classified according to a strict computerised algorithm designed by Walden et al., and the knee-up test was tested by non-expert examiners.

Results Among the 200 patients, 95 and 105 were classified as AIS C and AIS D, respectively. Overall, 126 and 74 patients demonstrated positive and negative results, respectively, when evaluated using the knee-up test. A total of 104 patients with positive results and 73 patients with negative results were classified as AIS D and AIS C, respectively. The sensitivity, specificity, positive predictive and negative predictive values of this test for all patients were 99.1, 76.8, 82.5 and 98.7, respectively.

Conclusions The knee-up test may allow easy and highly accurate estimation, without the need for special skills, of AIS classification for patients with incomplete CSCI.
\end{abstract}

\section{Introduction}

Precise classification of the neurological state of patients with acute spinal cord injury (SCI) is essential in determining the prognosis, therapeutic strategy and outcomes/ benefits from the interventions [1-10]. The American Spinal Injury Association (ASIA) published standards for neurological and functional classification of SCI in 1982 [11]. The International Standards for Neurological Classification of Spinal Cord Injury (ISNCSCI) was accepted and recommended by the International Medical Society of

Itaru Yugué

iyugue@orange.ocn.ne.jp

1 Department of Orthopaedic Surgery, Spinal Injuries Centre, Iizuka, Fukuoka, Japan

2 Department of Orthopaedic Surgery, Kyushu University, Fukuoka, Japan
Paraplegia (IMSOP) in 1992, and the ASIA Impairment Scale (AIS) based on the revised version of ISNCSCI [12, 13] is now used worldwide to determine motor and sensory impairments in patients with SCI. In order to accurately assess AIS, it is mandatory to determine the sensory level, sensory scores, motor level and strength of the key muscles using the ISNCSCI classification [14]. The ISNCSCI method was tested for its inter- and intra-rater reliabilities [15-26]. This method is slightly complicated, and several studies illustrated that training and experience may be required for accurate agreement $[15,20,21,25,26]$. Importantly, some studies reported that the reliability of sensory and motor components of ISNCSCI in patients with incomplete SCI was lower than that in patients with complete SCI $[15,19,20,22,26]$. In the patients with motor incomplete SCI, the most complicated task even after training was to distinguish AIS B from AIS C/D based on the motor sparing of more than three segments below the motor level [20, 24, 27]. Moreover, in the patients classified 
A
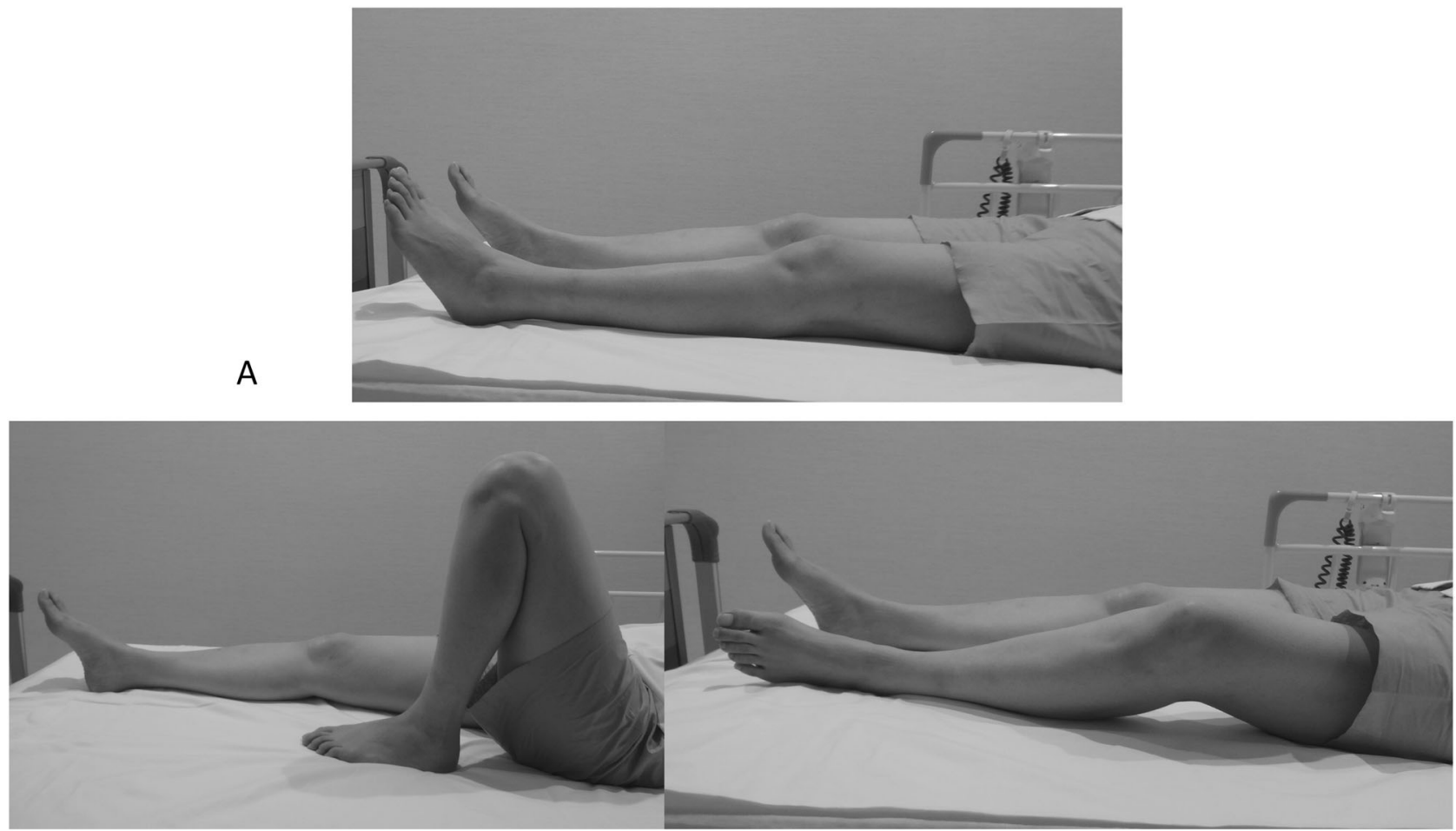

B

Fig. 1 a In the knee-up test, the patient was placed in the supine position. b Clinicians ask patients to lift up their knees off the bed. If patient was able to lift their knees to an upright position, then the

as AIS D after training, $\sim 15 \%$ of those was misclassified $[20,27]$. These results indicate that a very careful evaluation was mandatory to correctly assess AIS in patients with incomplete SCI. These patients often exhibit spontaneous motor function recovery; hence, an easy and quick to perform screening tool needs to be developed because a complete ISNCSCI examination in these patients might reach up to an hour, and frequent evaluation using the full ISNCSCI method is not practical in the early stage of injury.

We previously reported that the knee-up test was useful for the early detection of postoperative motor deficit [28] as well as hysterical paralysis [29]. This test is also thought to have a possibility to easily estimate the severity of paralysis. The purpose of this study is to verify the usefulness of estimating paralysis severity using the 'knee-up test' in patients with incomplete SCI, especially in distinguishing AIS C from D.

\section{Methods}

\section{Study population}

A total of 675 patients with cervical SCI (CSCI) were treated at the Department of Orthopaedic Surgery of the patient had a positive knee-up test result (left leg). $\mathbf{c}$ If the patient was unable to lift the knees up to the upright position, then the patient had a negative knee-up test result (left leg)

Spinal Injuries Centre from June 2005 to June 2016. The inclusion criteria were the following: (1) patients with traumatic CSCI verified using magnetic resonance imaging, (2) patients with motor incomplete CSCI determined according to the ISNSCI classification at the time of admission and (3) ability to adequately communicate. The medical records of 215 consecutive patients with acute motor incomplete CSCI, who were treated within 2 days after injury, were reviewed. Fifteen patients were excluded because some motor functions were not testable due to fracture and/or hypersensitivity of the extremities. The medical records of the remaining 200 patients were then analysed.

Informed consent was obtained from all individual participants included in the study.

\section{Manoeuvre of the knee-up test}

Patients were placed in the supine position, and the clinicians asked them to lift up their knees off the bed (Fig. 1a). If patients were able to lift their knees to an upright position, they were considered to have a positive knee-up test result (Fig. 1b). If patients were unable to do so, then the knee-up test had a negative result (Fig. 1c). Patient had a positive single knee-up test if he/she was able to lift at least one of 
his/her knees, whereas the patient was considered to have a negative single knee-up test if he/she was not able to lift either of his/her legs.

Patients were independently examined at the time of admission by two expert orthopaedic surgeons (I.Y. and T. U.), who had $>5$ years of experience in using the ISNCSCI method. At the same time, two non-expert residents who had $<1$ year of experience in using the ISNCSCI method performed the knee-up tests. They were blinded to the results obtained by the other observers.

\section{Key muscles for knee-up positive and relation between the key muscles and upper and lower extremities' muscle functions}

Considering that the physiologic continuity of the spinal cord long tract fibres is broken into CSCI, paralysis of one muscle is often linked to paralysis of the other muscles in the upper and lower extremities. Therefore, we analysed the key leg muscles that contributed positively to the knee-up test and the relationship between the motor scores of all key muscles and key leg muscles associated with the knee-up test.

\section{AIS classification}

Regarding AIS, data to be filled into the neurological worksheet were: sensory scores including light touch and pin prick, motor score for each segment, presence of voluntary anal contraction, and results of the knee-up test. Since 1980, non-key muscles, such as shoulder elevation, shoulder abductors, wrist flexors, finger extensors, hip adductors, hip abductors and long toe flexors, were examined and graded using the Manual Muscle Test. All data were collected prospectively. Given that the ISNCSCI methods were improved during our study period, to update the AIS classification, every parameter, including sensory score, motor score for each segment and presence of voluntary anal contraction of each patient, was entered into a personal computer, and the AIS of each patient was evaluated and verified by the computerised algorithm designed by Walden et al. [30]. after completing the data entry.

When a disagreement existed between the results of the single knee-up test and the results of AIS obtained by the two observers, the results were classified as single knee-up test negative and as AIS C.

\section{Statistical analysis}

The association between the result of the single knee-up test of a patient and the results of AIS was investigated. Fisher's exact test was used to compare categorical data. Odds ratio
(OR), and 95\% confidence interval (CI), sensitivity, specificity, positive predictive value (PPV), and negative predictive value (NPV) were calculated. The kappa statistic was used to assess the inter-observer agreement on the knee-up test.

To clarify the importance of the key leg muscles in maintaining the knee in its lifted position, the relationship between the result of the knee-up test and the strength of each key leg muscle was analysed using a multiple logistic regression model. Correlations between the motor scores of the significant key muscles and those of the other key muscles were analysed using Pearson's correlation coefficient. The correlation coefficient $(r)$ was interpreted as follows: value of $r$ between -1.0 and -0.7 or 1.0 and 0.7 : a strong linear relationship; between -0.7 and -0.5 or 0.5 and 0.7: a moderate linear relationship; and between -0.5 and -0.3 or 0.3 and 0.5 : a weak linear relationship [31]. All statistical analyses were performed using the JMP 11 statistical software package (SAS Institute Inc., Cary, NC, USA). A value of $p<0.05$ was considered to be statistically significant.

\section{Results}

Two hundred eligible patients (166 males, 34 females) were selected for inclusion in the final sample. All injuries were the result of blunt trauma. Mean patients' age was $62.4 \pm$ 15.6 years (mean $\pm \mathrm{SD}$ ) (range, 16-91 years). The consciousness level of all patients was normal. The mean interval between the day of injury and the day of evaluation was $0.8 \pm 0.75$ day (mean $\pm \mathrm{SD}$ ) (range, 0-2 days). The neurological status of each patient was evaluated at the time of admission. Neurological level of injury was C2 in 4 patients, C3 in 15, C4 in 104, C5 in 45, C6 in 25, C7 in 6 and C8 in 1 patient. Ninety-five of the 200 patients were classified as AIS C. The mean total upper motor score (TUEMS) was $11.95 \pm 1.14($ mean \pm SD) and mean total lower motor score (TLEMS) was 14.26 \pm 1.08 (mean \pm SD). According to Pouw et al. [32], traumatic central cord syndrome (TCCS) was defined as a TUEMS of 10 points less than the TLEMS; 30 in 95 patients (31.58\%) had TCCS. One hundred and five of the 200 patients were classified as AIS D. The mean TUEMS was $30.10 \pm 1.07$ $($ mean $\pm \mathrm{SD})$ and mean TLEMS was $41.78 \pm 1.02$ (mean \pm SD). Fifty-five in the 105 patients $(52.38 \%)$ had TCCS. Both mean TUEMS and TLEMS in the AIS D group were statistically significantly higher than those in the AIS C group (TUEMS: $p<0.0001$, TLEMS: $p<0.0001$ ) and the percentage of TCCS in the AIS C group was statistically significantly higher than that in the AIS D group $(p=$ 0.0041) (Table 1). The kappa coefficient for the AIS between two expert orthopaedic surgeons was $0.99(p<$ 
Table 1 Demographic characteristics according to the American Spinal Injury Association impairment scale

\begin{tabular}{|c|c|c|c|}
\hline Patients & $\begin{array}{l}\text { C } \\
95 \text { patients }\end{array}$ & $\begin{array}{l}\mathrm{D} \\
105 \text { patients }\end{array}$ & $p$ \\
\hline Sex & $\begin{array}{l}\text { Male: } 77 ; \\
\text { female: } 18\end{array}$ & $\begin{array}{l}\text { Male: } 89 ; \\
\text { female: } 16\end{array}$ & 0.572 \\
\hline Age (years) & $\begin{array}{l}64.1 \pm 1.59 \\
(\text { mean } \pm \mathrm{SD})\end{array}$ & $\begin{array}{l}60.8 \pm 1.52 \\
(\text { mean } \pm \text { SD) }\end{array}$ & 0.145 \\
\hline TUEMS & $\begin{array}{l}11.95 \pm 1.14 \\
(\text { mean } \pm S D)\end{array}$ & $\begin{array}{l}30.10 \pm 1.07 \\
(\text { mean } \pm S D)\end{array}$ & $<0.0001^{*}$ \\
\hline TUEMS: 0-10 & 53 patients & 7 patients & \\
\hline $\begin{array}{l}\text { TUEMS: } \\
11-20\end{array}$ & 27 patients & 20 patients & \\
\hline $\begin{array}{l}\text { TUEMS: } \\
21-30\end{array}$ & 11 patients & 26 patients & \\
\hline $\begin{array}{l}\text { TUEMS: } \\
31-40\end{array}$ & 4 patients & 23 patients & \\
\hline $\begin{array}{l}\text { TUEMS: } \\
41-50\end{array}$ & No patient & 29 patients & \\
\hline TLEMS & $\begin{array}{l}14.26 \pm 1.08 \\
(\text { mean } \pm S D)\end{array}$ & $\begin{array}{l}41.78 \pm 1.02 \\
(\text { mean } \pm S D)\end{array}$ & $<0.0001$ \\
\hline TLEMS: 0-10 & 41 patients & 1 patient & \\
\hline TLEMS: $11-20$ & 25 patients & 2 patients & \\
\hline TLEMS: 21-30 & 22 patients & 15 patients & \\
\hline TLEMS: 31-40 & 6 patients & 20 patients & \\
\hline TLEMS: 41-50 & 2 patients & 67 patients & \\
\hline TCCS & $\begin{array}{l}\text { TCCS: } 30 \text {; } \\
\text { non-TCCS: } 65\end{array}$ & $\begin{array}{l}\text { TCCS: } 55 \text {; } \\
\text { non-TCCS: } 50\end{array}$ & $0.0041^{* *}$ \\
\hline
\end{tabular}

TUEMS total upper motor scores, TLEMS total lower motor scores, TCCS traumatic central cord syndrome

${ }^{*}$ Unpaired $t$ test: $p<0.05$

** Fisher's exact test: $p<0.05$

0.0001). There was no difference in the knee-up test derived by the two non-expert examiners.

One hundred and twenty-six patients exhibited positive results when evaluated using the single knee-up test, whereas 74 patients exhibited negative results. The mean TUEMS was $27.03 \pm 1.10$ (mean \pm SD) and the mean TLEMS was $39.16 \pm 0.94$ (mean $\pm \mathrm{SD}$ ) in the knee-up positive group, whereas the mean TUEMS was $12.04 \pm$ 1.44 (mean \pm SD) and the mean TLEMS was $10.91 \pm 1.24$ (mean $\pm \mathrm{SD}$ ) in the knee-up negative group. Seventy-one in 126 patients $(56.35 \%)$ had TCCS in the positive group and 14 in 74 patients (18.92\%) had TCCS in the negative group. Both mean TUEMS and TLEMS in the knee-up positive group were statistically significantly higher than those in the knee-up negative group (TUEMS: $p<0.0001$, TLEMS: $p$ $<0.0001)$ and the percentage of TCCS in the negative group was statistically significantly higher than that in the positive group $(p<0.0001)$ (Table 2$)$. One hundred and four of the patients with positive results were classified as AIS D. Seventy-three patients with negative single knee-up test were classified as AIS C (Fisher's exact $p<0.0001$; OR, 345.1; 95\% CI, 45.5-2617.7) (Table 3). The sensitivity, specificity, PPV and NPV of this test for all cases were 99.1, 76.8, 82.5 and 98.7, respectively. Concerning the relationship between the knee-up test and TCCS (Table 4), the sensitivity, specificity, PPV and NPV of this test were $83.5,52.17,56.35$ and 81.03 , respectively.

Multiple logistic regression demonstrated that hip flexors ( $p<0.0001$; OR, 5.87; 95\% CI, 2.94-13.6), hip adductors $(p=0.0352 ;$ OR, 2.11; 95\% CI, 1.04-4.29) and hip abductors ( $p=0.0291$; OR, 1.86; 95\% CI, 1.06-3.49) were statistically significant for the key leg muscles that contributed positively to the knee-up test (Table 5). When the muscles were restricted only to the ASIA key muscles, multiple logistic regression demonstrated that hip flexors ( $p$ $<0.0001$; OR, 10.9; 95\% CI, 5.9-23.4) and ankle dorsiflexors $(p=0.0255$; OR, 1.6 ; 95\% CI, 1.1-2.6) were statistically significant for the key leg muscles that contributed positively to the knee-up test (Table 6).

The motor score of both hip flexors (Table 7) and ankle dorsiflexors (Table 8) showed significantly strong correlations with that of the other key muscles in the lower extremities, and significantly moderate correlations with that of the elbow extensors, finger flexors and finger abductors. The motor scores of hip flexors and ankle dorsiflexors showed a significantly weak correlation compared to those of the elbow flexors and wrist extensors.

\section{Discussion}

In the present study, we demonstrated the usefulness of the knee-up test for AIS assessment in patients with motor incomplete CSCI. To correctly assess AIS, several complicated examination steps are required. First, sensory (ie, light touch and pin prick sensation) and motor examinations for the right and left extremities are determined according to the ISNCSCI method. Second, NLI, which is the most caudal segment of the cord with intact sensation and antigravity muscle function strength, should be determined. Third, AIS is evaluated using these sensory and motor findings in a comprehensive manner. Mastery of skills needed for each step in the ISNCSCI method is required for clinicians as described above, indicating that examination skills might influence the result of AIS grading. Both AIS C and $\mathrm{D}$ indicate that motor function is preserved below the $\mathrm{NLI}$; however, the distinction between them is not always easy. The function of more than half of the key muscles below the single NLI have a grade of $<3$ (grades $0-2$ ) is classified as AIS C, whereas the case wherein at least half (half or more) of the key muscles below the NLI have a grade greater or equal to 3 (grades 3-5) is classified as AIS D [14]. 
Table 2 Demographic characteristics according to the result of knee-up test

\begin{tabular}{llll}
\hline Patients & $\begin{array}{l}\text { Positive } \\
126 \text { patients }\end{array}$ & $\begin{array}{l}\text { Negative } \\
74 \text { patients }\end{array}$ & $p$ \\
\hline Sex & Male: $107 ;$ female: 19 & Male: 59 ; female: 15 & 0.436 \\
Age (years) & $61.06 \pm 1.39($ mean \pm SD) & $64.58 \pm 1.80($ mean \pm SD) & 0.123 \\
TUEMS & $27.03 \pm 1.10($ mean \pm SD) & $12.04 \pm 1.44($ mean \pm SD) & $<0.0001^{*}$ \\
TLEMS & $39.16 \pm 0.94($ mean \pm SD) & $10.91 \pm 1.24($ mean \pm SD) & $<0.0001^{*}$ \\
TCCS & TCCS: $71 ;$ non-TCCS: 55 & TCCS: 14 ; non-TCCS: 60 & $<0.0001^{* *}$ \\
\hline
\end{tabular}

TUEMS total upper motor scores, TLEMS total lower motor scores, TCCS traumatic central cord syndrome

* Unpaired $t$ test: $p<0.05$

** Fisher's exact test: $p<0.05$
Table 3 Relationship between the American Spinal Injury Association impairment scale and the knee-up sign findings

\begin{tabular}{llll}
\hline & \multicolumn{3}{l}{ The ASIA impairment scale } \\
\cline { 2 - 4 } & $\mathrm{C}(n)$ & $\mathrm{D}(n)$ & Total $(n)$ \\
\hline Knee-up test positive & 22 & 104 & 126 \\
Knee-up test negative & 73 & 1 & 74 \\
Total & 95 & 105 & 200 \\
\hline
\end{tabular}

Table 4 Relationship between the traumatic central cord syndrome and knee-up test findings

\begin{tabular}{llll}
\hline & TCCS $(n)$ & Non-TCCS $(n)$ & Total $(n)$ \\
\hline Knee-up test positive & 71 & 55 & 126 \\
Knee-up test negative & 14 & 60 & 74 \\
Total & 85 & 115 & 200 \\
\hline
\end{tabular}

TCCS traumatic central cord syndrome

Table 5 Multiple logistic regression by combined muscle functions for the positive knee-up test (with the non-key muscles)

\begin{tabular}{llll}
\hline $\begin{array}{l}\text { Combined muscle } \\
\text { functions }\end{array}$ & $p$ & $\begin{array}{l}\text { Odds } \\
\text { ratio }\end{array}$ & $\begin{array}{l}95 \% \text { confidence } \\
\text { interval }\end{array}$ \\
\hline Hip flexors & $<0.0001^{*}$ & 5.88 & $2.94-13.6$ \\
Hip adductors & $0.0353^{*}$ & 2.10 & $1.05-4.29$ \\
Hip abductors & $0.0292^{*}$ & 1.85 & $1.06-3.49$ \\
Knee extensors & 0.3549 & 0.78 & $0.45-1.30$ \\
Ankle dorsiflexors & 0.1745 & 1.35 & $0.87-2.15$ \\
Long toe extensors & 0.9054 & 1.03 & $0.59-1.77$ \\
Ankle plantar flexors & 0.7574 & 1.09 & $0.63-1.86$ \\
\hline
\end{tabular}

${ }^{*} P<0.05$

In patients with acute CSCI, some merits exist for accurate distinction between AIS C and D. For example, AIS $\mathrm{C}$ is a more appropriate neurological condition in validating the efficacy of treatment for neurological improvement [1-4]. In addition, acute complications were found to develop more frequently in patients with AIS C than in those with AIS D $[5,6]$. Therefore, early distinction
Table 6 Multiple logistic regression by combined muscle functions for the positive knee-up test

\begin{tabular}{llll}
\hline $\begin{array}{l}\text { Combined muscle } \\
\text { functions }\end{array}$ & $p$ & $\begin{array}{l}\text { Odds } \\
\text { ratio }\end{array}$ & $\begin{array}{l}95 \% \text { confidence } \\
\text { interval }\end{array}$ \\
\hline Hip flexors & $<0.0001^{*}$ & 10.85 & $5.9-23.4$ \\
Knee extensors & 0.7918 & 0.93 & $0.57-1.52$ \\
Ankle dorsiflexors & $0.0255^{*}$ & 1.64 & $1.07-2.59$ \\
Long toe extensors & 0.8930 & 0.96 & $0.57-1.62$ \\
Ankle plantar flexors & 0.3503 & 1.26 & $0.77-2.07$ \\
\hline
\end{tabular}

${ }^{*} P<0.05$

Table 7 Correlation between the motor score of hip flexors and those of the other key muscles

\begin{tabular}{lll}
\hline Key muscle & $p$ & Correlation coefficient \\
\hline Elbow flexors & $<0.0001^{*}$ & 0.357 \\
Wrist extensors & $<0.0001^{*}$ & 0.459 \\
Elbow extensors & $<0.0001^{*}$ & 0.566 \\
Finger flexors & $<0.0001^{*}$ & 0.564 \\
Small finger abductors & $<0.0001^{*}$ & 0.509 \\
Knee extensors & $<0.0001^{*}$ & 0.857 \\
Ankle dorsiflexors & $<0.0001^{*}$ & 0.844 \\
Long toe extensors & $<0.0001^{*}$ & 0.807 \\
Ankle plantar flexors & $<0.0001^{*}$ & 0.836 \\
\hline
\end{tabular}

${ }^{*} P<0.05$

between AIS C and D is important to evaluate treatment outcomes and complication risk during the early stage of injury, especially the need for tracheostomy [5] in patients with incomplete CSCI.

Several studies reported the inter-rater and intra-rater reliability of ISNCSCI [15-26]. Generally, intra-rater and inter-rater agreements among trained or experienced raters were acceptable; [17, 21-23] however, even for trained examiners, the agreements of sensory and/or motor examination were less reliable in patients with an incomplete SCI than in those with a complete SCI [19, 22]. In addition, 
Table 8 Correlation between the motor score of ankle dorsiflexors and those of the other key muscles

\begin{tabular}{lll}
\hline Key muscle & $p$ & Correlation coefficient \\
\hline Elbow flexors & $<0.0001^{*}$ & 0.270 \\
Wrist extensors & $<0.0001^{*}$ & 0.410 \\
Elbow extensors & $<0.0001^{*}$ & 0.520 \\
Finger flexors & $<0.0001^{*}$ & 0.534 \\
Small finger abductors & $<0.0001^{*}$ & 0.508 \\
Hip flexors & $<0.0001^{*}$ & 0.845 \\
Knee extensors & $<0.0001^{*}$ & 0.837 \\
Long toe extensors & $<0.0001^{*}$ & 0.896 \\
Ankle plantar flexors & $<0.0001^{*}$ & 0.858 \\
\hline
\end{tabular}

${ }^{*} P<0.05$

although several studies have reported that training improved accuracy of agreement [15, 16, 18, 20, 24-26], efficacy was significantly lower in incomplete than in complete SCI [15, 16, 20, 24-26]. For example, Chafetz et al. [20] reported that training improved correct classification of patients with AIS C from 29 to $54 \%$ and of those with AIS D from 37 to $84 \%$, and stated clearly that accurate classification of AIS designation remained unacceptably low even after training. These reports suggested that nonexperts should receive proper training before using the ISNCSCI in clinical practice [20, 25]. In this study, interrater agreements among two expert orthopaedic surgeons who had 5 years or more of experience in using the ISNCSCI method in $>400$ SCI cases were high enough. This means that to be able to correctly classify patients with motor incomplete CSCI, proper training and greater level of experience are needed.

In contrast, the knee-up test presented in this study does not require special skills when performing. We previously reported that the knee-up test was useful for the early detection of postoperative motor deficit [28] as well as hysterical paralysis [29]. In the current study, no patient data overlapped with the previous studies [28, 29]. In a previous study [28], hip adductors and abductors were important muscles in lifting the knees up (knee-up test positive) and in keeping the knee in this position. However, these muscles were not used to analyse their correlations with the key muscles in the current study, because they were not key muscles of the ISNSCI classification. The knee-up test also provides easy distinction between AIS C and $\mathrm{D}$ in patients with motor incomplete CSIC. If the patient could not lift his/her knees in either legs to an upright position (single knee-up test negative), this patient was classified as AIS C with $98.6 \%$ probability; on the other hand, if the patient was able to lift his/her knee in at least one leg (single knee-up test positive) to an upright position, this patient was classified as AIC D with $82.5 \%$ probability.
Although the knee-up test was useful to estimate AIS C or $\mathrm{D}$, the purpose of this test was not to promote shortcuts for clinical evaluations but to screen the severity of motor incomplete CSCI for non-expert examiners using an easy clinical tool. The knee-up test is thought to be useful to estimate TCCS. However, with regard to the relationship between the knee-up test and TCCS, the sensitivity, specificity, PPV and NPV of this test were 83.5, 50.89, 56.35 and 80.26 , respectively. These results suggest that the knee-up test is more useful for the distinction between AIS C and D in patients with incomplete CSCI than for the distinction of TCCS.

Even though the single knee-up test was positive in 126 patients, only 22 were classified as AIS C. This might explain the relatively low specificity of the knee-up test. Among these patients, $15(68 \%)$ had a one side positive test result. When a single positive test is divided into two categories: both side positive (73 of 80 cases $(91 \%)$ were AIS D) and one side positive (31 of 46 cases (67\%) were AIS D), the percentage of correctly identified cases with AIS D increased; however, the sensitivity and specificity of the test could not be calculated. Regardless of its relatively low specificity, these correction rates of classification (98.6\% and $82.5 \%$ ) are high enough to be compared to the results of the trained raters [15, 20, 24, 27].

In this study, we analysed the motor score of the key muscles necessary for lifting the knee using a multiple logistic regression model and found that the hip flexors and ankle dorsiflexors were the statistically significantly associated with the knee-up test (Table 2). Notably, the motor score of these muscles had a strongly positive correlation with the score of the key muscles in the lower limbs and a moderately positive correlation with that of the key muscles of upper limbs. These results suggest that a simple examination using the knee-up test yields general information of paralysis in extremities, especially in the legs, with great accuracy. Alternatively, the lower-limb muscles, besides the hip flexors and ankle dorsiflexors, had a moderate correlation with the upper-limb muscles. These results indicate that patients with a positive knee-up test most likely had a substantial motor function in the upper and lower limbs. Given that the distinction between AIS C and D is that whether at least half of the key muscle functions below the NLI have a muscle grade of $>3(5-3)$ or $<3(2-0)$, there is a high possibility that patients with positive knee-up test are classified as AIS D. For this reason, this test could estimate the AIS classification with high probability in patients with incomplete CSCI.

There are several possible limitations associated with this study. First, the sample size was relatively small. Second, the knee-up test was evaluated at a single institution. Third, this test is not applicable to patients with pelvic fracture and/or lower-limb fracture who are unable to lift up their 
knees. Fourth, because only patients in a very acute stage were examined, the results of this study cannot be transferred to patients in the chronic stage because of severe spasticity, joint contractures, pain and heterotopic ossifications. Finally, the knee-up test is not useful for the patient with CSCI who has absent motor function of the lower extremities but sacral sensory sparing with sparing of motor function more than three levels below the motor level for that side of the body; the patient is then classified as AIS C. When the patient had no leg motor function but who has sacral sensory sparing, adequate ISNCSCI examination is mandatory to precisely classify AIS. Despite these limitations, we believe that this test is useful at bedside for nontrained clinicians who are not familiar with the ISNCSCI method. In addition, this test is applicable for the patients who have difficulties with precise communication and neurological evaluation.

In conclusion, the sensitivity, specificity, PPV and NPV of this test for distinction between AIS C and D in patients with motor incomplete CSCI were 99.1, 76.8, 82.5 and 98.7, respectively.

\section{Compliance with ethical standards}

Conflict of interest The authors declare that they have no conflict of interest.

\section{References}

1. Kejžar N, Vesel M, Al Mawed S, Dobravec M, Herman S, et al. Neurological recovery after traumatic cervical spinal cord injury is superior if surgical decompression and instrumented fusion are performed within $8 \mathrm{~h}$ versus 8 to $24 \mathrm{~h}$ after injury: a single center experience. J Neurotrauma. 2015;32:1385-92.

2. Mazaki T, Ito Y, Sugimoto Y, Koshimune K, Tanaka M, Ozaki T, Dose laminoplasty really improve neurological status in patients with cervical spinal cord injury without bone and disc injury? A prospective study about neurological recovery and early complications. Arch Othop Trauma Surg. 2013;133:1401-5.

3. Chikuda H, Seichi A, Takeshita K, Matsunaga S, Watanabe M, Nakagawa Y, et al. Acute cervical spinal cord injury complicated by preexisting ossification of the posterior longitudinal ligament: a multicenter study. Spine. 2011;36:1453-8.

4. Kawano O, Ueta T, Shiba K, Iwamoto Y, Outcome of decompression surgery for cervical spinal cord injury without bone and disc injury in patients with spinal cord compression: a multicenter prospective study. Spinal Cord. 2010;48:548-53.

5. Menaker J, Kufera JA, Glaser J, Stein DM, Scalea TM, Admission ASIA motor score predicting the need for tracheostomy after cervical spinal cord injury. J Trauma Acute Care Surg. 2013;75:629-34.

6. Grossman RG, Frankowski RF, Burau KD, Toups EG, Crommett $\mathrm{JW}$, et al. Incidence and severity of acute complications after spinal cord injury. J Neurosurg Spine. 2012;17(1 Suppl):119-28.

7 Nakashima H, Yukawa Y, Ito K, Machino M, Kato F, Mechanical patterns of cervical injury influence postoperative neurological outcome: a verification of the allen system. Spine. 2011;36: E441-6.
8 Nakashima H, Yukawa Y, Ito K, Machino M, El Zahlawy H, Kato F, Posterior approach for cervical fracture-dislocations with traumatic disc herniation. Eur Spine J. 2011;20:387-94.

9 van Middendorp JJ, Goss B, Urquhart S, Atresh S, Williams RP, Schuetz M, Diagnosis and prognosis of traumatic spinal cord injury. Global Spine J. 2011;1:1-8.

10. Fehlings MG, Vaccaro A, Wilson JR, Singh A, W Cadotte D, Harrop JS, et al. Early versus delayed decompression for traumatic cervical spinal cord injury: results of the Surgical Timing in Acute Spinal Cord Injury Study (STASCIS). PLoS ONE. 2012;7:e32037

11. American Spinal Injury Association. Standards for neurological classification of spinal injured patients. Chicago: ASIA; 1982.

12. Kirshblum SC, Burns SP, Biering-Sorensen F, Donovan W, Graves DE, Jha A, et al. International standards for neurological classification of spinal cord injury (revised 2011). J Spinal Cord Med. 2011;34:535-46.

13. Kirshblum S, Waring W 3rd. Updates for the International Standards for Neurological Classification of Spinal Cord Injury. Phys Med Rehabil Clin N Am. 2014;25:505-17.

14. International Standards for the Neurological Classification of Spinal Cord Injury Revised. Booklet. Atlanta: American Spinal Injury Association; 2011.

15 Cohen ME, Ditunno JF,Jr, Donovan WH, Maynard FM,Jr, A test of the 1992 International Standards for Neurological and Functional Classification of Spinal Cord Injury. Spinal Cord. 1998;36:554-60.

16. Jonsson M, Tollbäck A, Gonzales H, Borg J. Inter-rater reliability of the 1992 international standards for neurological and functional classification of incomplete spinal cord injury. Spinal Cord. 2000;38:675-9.

17. Savic G, Bergström EM, Frankel HL, Jamous MA, Jones PW, Inter-rater reliability of motor and sensory examinations performed according to American Spinal Injury Association standards. Spinal Cord. 2007;45:444-51.

18. Mulcahey MJ, Gaughan J, Betz RR, Vogel LC. Rater agreement on the ISCSCI motor and sensory scores obtained before and after formal training in testing technique. J Spinal Cord Med. 2007;30 (Suppl 1):S146-9.

19. Marino RJ, Jones L, Kirshblum S, Tal J, Dasgupta A. Reliability and repeatability of the motor and sensory examination of the international standards for neurological classification of spinal cord injury. J Spinal Cord Med. 2008;31:166-70.

20. Chafetz RS, Vogel LC, Betz RR, Gaughan JP, Mulcahey MJ. International standards for neurological classification of spinal cord injury: training effect on accurate classification. J Spinal Cord Med. 2008;31:538-42.

21. Mulcahey MJ, Gaughan J, Betz RR, Agreement of repeated motor and sensory scores at individual myotomes and dermatomes in young persons with complete spinal cord injury. Spinal Cord. 2009;47:56-61.

22. Chafetz RS, Gaughan JP, Vogel LC, Betz R, Mulcahey MJ. The International Standards for Neurological Classification of Spinal Cord Injury: intra-rater agreement of total motor and sensory in the pediatric population. J Spinal Cord Med. 2009;32:157-61.

23. Mulcahey MJ, Gaughan JP, Chafetz RS, Vogel LC, Samdani AF, Betz RR, Interrater reliability of the international standards for neurological classification of spinal cord injury in youths with chronic spinal cord injury. Arch Phys Med Rehabil. 2011;92:1264-9.

24. Schuld C, Wiese J, Franz S, Putz C, Stierle I, Smoor I, et al. Effect of formal training in scaling, scoring and classification of the International Standards for Neurological Classification of Spinal Cord Injury. Spinal Cord. 2013;51:282-8. 
25. Liu N, Zhou MW, Krassioukov AV, Biering-Sørensen F, Training effectiveness when teaching the International Standards for Neurological Classification of Spinal Cord Injury (ISNCSCI) to medical students. Spinal Cord. 2013;51:768-71.

26. Hales M, Biros E, Reznik JE, Reliability and validity of the sensory component of the International Standards for Neurological Classification of Spinal Cord Injury (ISNCSCI): a systematic review. Top Spinal Cord Inj Rehabil. 2015;21:241-9.

27. Schuld C, Franz S, van Hedel HJ, Moosburger J, Maier D, Abel R, et al. International Standards for Neurological Classification of Spinal Cord Injury: classification skills of clinicians versus computational algorithms. Spinal Cord. 2015;53: 324-31.

28. Yugué I, Okada S, Masuda M, Ueta T, Maeda T, Shiba K. "Kneeup test" for easy detection of postoperative motor deficits following spinal surgery. Spine J. 2016;16:1437-44.
29. Yugué I, Shiba K, Ueta T, Iwamoto A. New clinical evaluation for hysterical paralysis. Spine. 2004;29:1910-3.

30. Walden K, Bélanger LM, Biering-Sørensen F, Burns SP, Echeverria $\mathrm{E}$, Kirshblum $\mathrm{S}$, et al. Development and validation of a computerized algorithm for International Standards for Neurological Classification of Spinal Cord Injury (ISNCSCI). Spinal Cord. 2016;54:197-203.

31. Statistic for dummies, Part V: Interpreting the correlation, 2nd ed., 284 (Hoboken: Wiley Publishing Inc.)

32. Pouw MH, van Middendorp JJ, van Kampen A, Hirshfeld S, Veth RP, Curt A, et al. Diagnosis criteria of traumatic central cord syndrome. Part 1: a systematic review of clinical descriptors and scores. Spinal Cord. 2010;48:652-6. 